\title{
E.E.G. ABNORMALITIES FROM THE TEMPORAL LOBE STUDIED WITH SPHENOIDAL ELECTRODES
}

\author{
BY \\ G. PAMPIGLIONE and J. KERRIDGE \\ From the Institute of Psychiatry, Maudsley Hospital, London
}

In the last few years applied electrophysiology has played an increasing part in the routine clinical work of many neurological and psychiatric centres. Combined clinical and electrophysiological observations have shown the problem of the epilepsies to be very intricate, and the study of abnormalities of cerebral function related to the initiation and spread of an epileptic seizure still largely awaits development of new techniques. The seizures which Hughlings Jackson (Taylor, 1931) classified in the uncinate group (and which more recent workers have called either "psychomotor" or "temporal lobe" epilepsy) have lately aroused an increasing interest. (The literature is reviewed in papers by Penfield and Jasper, 1954 ; Hill, 1953 ; Meyers, 1954 ; Gastaut and others, 1953; Magnus, 1954). Routine clinical electroencephalography has contributed to the study of these types of seizures but only the posterior half or two-thirds of the lateral aspect of the temporal lobe may be explored with scalp electrodes. Anatomical considerations suggest that the activity of the anterior third of the temporal lobe, and particularly that of its inferior and uncal areas, cannot be satisfactorily recorded with electrodes placed on the skin (scalp or zygoma) or even in the pharynx or in the external auditory meatus.

The region of the foramen ovale appeared to be a suitable area easily reached, from which to record the activity of the anterior inferior regions of the temporal lobe. Jasper (1949) mentioned the use of needle electrodes in the region of the greater wing of the sphenoid (" ala magna" electrodes) introduced by Kristensens and Reyes (1949). Penfield and Jasper (1954) show an $x$-ray picture of these electrodes introduced by the anterior approach. The insertion of needles close to the foramen ovale with an anterior approach is, however, a rather elaborate procedure (Penman, 1953) with some risk of entering the cranial cavity through the foramen.

In 1951 D. P. Jones showed to the E.E.G. Society records taken with sphenoidal needle electrodes using the lateral approach. Pertuiset and Capde-
vielle-Arfel (1951) and Kerridge (1952) reported on their experience with similar methods, but in all these communications the technical details and observations are scanty.

A simple and safe method with slight modification of those previously mentioned has been followed in examining our series of patients. Needle electrodes are introduced through the skin under the zygomatic arch to the vicinity of the foramen ovale. The method described here has become part of the routine investigation of cases in which on clinical or electroencephalographic (E.E.G.) grounds an "epileptogenic abnormality" of one or both temporal lobes is suspected (Hill, 1953 ; Falconer, Hill, Meyer, Mitchell, and Pond, 1955). This paper presents a summary of our experience of 250 consecutive records obtained from 166 patients using this technique up to June, 1953.

\section{Material}

All patients had had previous routine E.E.G. investigations (in some as many as 15 records) over a number of years with a total of 824 records. Most of our patients (the majority being under the care of Dr. D. Hill and Dr. D. A. Pond) were selected on clinical grounds irrespective of the previous E.E.G. findings. Most of them had a history of seizures of one or more types considered to be commonly associated with abnormality of function of the temporal lobe; for example, visceral, epigastric, olfactory or gustatory aura, " dreamy states ", or sudden feelings of indescribable fear, any of which may occur either as an isolated phenomenon or else precede a momentary arrest of movement, a simple or complex automatism, or a generalized convulsion. Other patients were investigated because their fits were facilitated by sleep or precipitated by emotion, or because speech disturbances occurred before or after an attack. In yet others, complex, organized, short-lived hallucinations had occurred or else there had been outbursts of violent behaviour with partial amnesia.

As in other epileptics the scalp E.E.G. abnorma- 
lities had been variable in site and severity over a period of time. In some instances there had been generalized E.E.G. abnormalities, in others the abnormalities were recorded mainly from one or both temporal regions. Cases with an obvious short duration spike focus outside the temporal areas were usually not re-examined with this technique unless the patient had more than one kind of attack. Patients with a history of attacks of doubtful nature either with normal or with abnormal scalp E.E.G.s were included as well as some patients who had episodes of altered behaviour either with or without alleged amnesia.

Rarely, in the present series, the indication for proceeding to a " sphenoidal recording " was based on E.E.G. findings : (1) Some non-focal abnormality over the scalp of the inferior fronto-temporal regions ; (2) the presence of bilaterally synchronous runs of rhythmic 2 to $6 \mathrm{c}$./s. waves; (3) focal abnormalities with a tendency to shift about the fronto-temporal regions.

\section{Preparation of the Electrodes and Technique of Insertion}

The aim is to insert a needle electrode so that its tip lies in proximity to the foramen ovale, i.e., fairly close to the uncal region and not very far from the tip of the temporal lobe and the region of the anterior part of the hippocampal and fusiform convolutions (Fig. 1). The technique employed is a slight modification of that commonly used for the lateral approach to the third division of the trigeminal nerve but the tip of the needle electrode should come to lie just anterior to, and below, the foramen ovale avoiding the nerve.

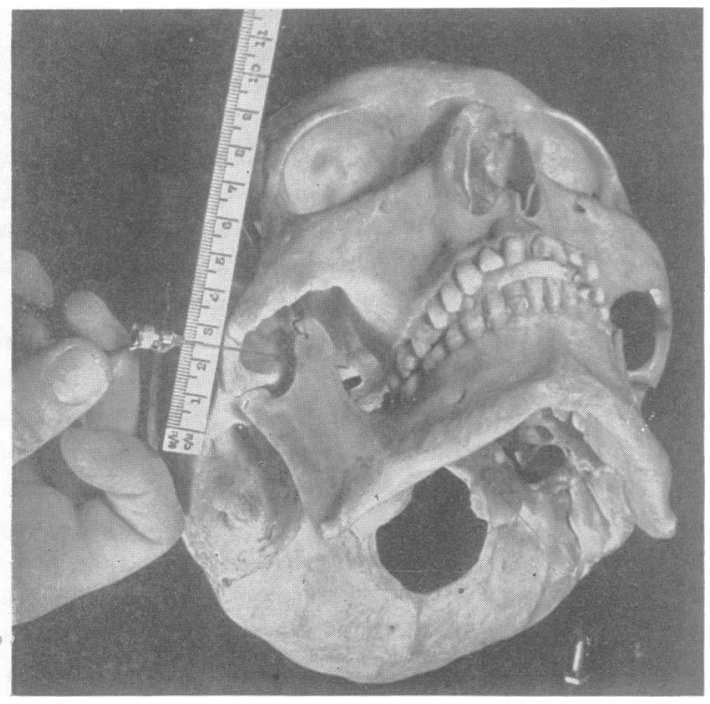

Fig. 1.-The insulated needle electrode is inserted just below the zygomatic arch and its tip lies anterior to, and below, the foramen ovale in the infratemporal fossa.

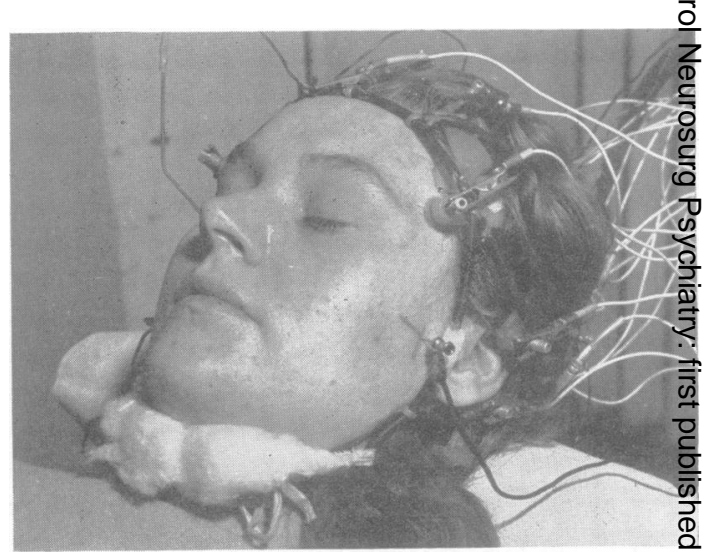

Fig. 2.-A patient with sphenoidal and pharyngeal electrodes inserted. Note also the electrode in the concha of the ear whyte little if any muscle artefact appears. Some of the other electrodfs have been removed.

An ordinary hypodermic steel needle $5 \mathrm{~cm}$. long a $0.6 \mathrm{~mm}$. in diameter (gauge 23) was insulated, except for $1 \mathrm{~mm}$. at the tip, with a bakelite varnish which w withstand boiling. The insulating coat was prepared with "darmarda lacquer Grade L 3128 " and a thimer obtainable from Bakelite Ltd. (London). The varnish is diluted one part in three of thinner. A first coat is p ph the needle, which is then baked at $100^{\circ} \mathrm{C}$. for काifise minutes. After a second coat the needle is aganh baked at $100^{\circ} \mathrm{C}$. for five minutes. A third coat is ap lieg and the needle is baked for 25 minutes at $150^{\circ} \mathrm{C}$. IT insulation is scraped off for about $1 \mathrm{~mm}$. atothe tip of the needle. A light flexible lead is soldered to the hilt of the needle. This ensures good permanent contags, avoids displacement of the needle with heavy crocodile clips, and permits of a quick extraction of the needle by pulling the lead in case of emergency. The needles carn be safely washed and boiled, with stilette in situ, wrapp $\overrightarrow{c d}$ in gauze for sterilization. It is advisable to have at le three or four needles prepared since flaws in the insulatign coat may be noticed at the last moment.

The patient should lie down comfortably on a coue and should have an empty bladder, as recording may last over one hour. Edentulous patients are asked retain their dentures, at least during the insertion of the needles, in order to avoid narrowing of the space between the zygomatic arch and the mandibular notch.

The skin on both sides of the face is cleaned with alcohol and marked with a sterile coloured solution, e.g., methylene blue or gentian violet. An oral probe with a mark at $2.5 \mathrm{~cm}$. from one end is used as a ruler. Another oral probe with a small piece of cotton wool dipped in the coloured solution is used for marking the skin. The point of insertion is marked at $2.5 \mathrm{~cm}$. anterior to the incisura intertragica and about $2 \mathrm{~mm}$. below inferior margin of the zygomatic arch. When this margin cannot be easily palpated, the mark can be made along a line from the incisura intertragica to the point rof attachment of the ala nasi (Fig. 2). In patients with vo 0 small faces and in children (four were examined betweent 
the ages of 12 to 15 years, none below 12 in this series) the distance from the incisura intertragica may be less than $2.5 \mathrm{~cm}$. (even near to $2 \mathrm{~cm}$.). Care should be taken that the skin is not displaced by the electrode cap, or by the patient smiling or grimacing, or by the operator's finger. It is important in this connexion to palpate again the inferior margin of the zygomatic arch at the level of the mark as the needle has to pass just below the arch. If desired, the skin and subcutaneous tissue may be anaesthetized with $2 \%$ procaine. Deep infiltration with anaesthetic should be avoided. When the patient is sufficiently cooperative it seems advisable to insert the needle without local anaesthetic, with the advantage of quicker procedure, no marked difference in pain between the introduction of the anaesthesia needle and the thin needle electrode, and no displacement of the marking either by the fluid injected or by a small subcutaneous collection of blood.

The needle electrode (without stilette) is then inserted at the marked point at right angles to a sagittal plane. The aponeurosis of the masseter muscle is felt with the tip of the needle as a moderately hard tissue which suddenly gives way. The patient often perceives "a peculiar clicking noise" when the fascia is penetrated. The electrode is gently introduced further in the same direction until it hits the bone (about $41 \mathrm{~cm}$. deep). When bone is felt superficially, then either the zygomatic arch (insertion too far up) or the mandibular bone (too far down) is met ; this is often due to displacement of the skin, and thus of the mark, during insertion. These errors should be corrected by reinserting the needle. The floor of the skull may be met if the needle is directed upwards. Tilting the needle may stretch the masseter and fascia. If no bone is felt by the time the needle has reached a depth of $4 \frac{1}{2}$ to $5 \mathrm{~cm}$. in an average face, it can be left in position and it will not be far away from the bone (either the medial wall of the infratemporal fossa or the upper portion of the lateral pterygoid lamina). There is no need for the electrode to remain in contact with the bone and the record is more satisfactory if the needle is not quite in contact with it. The tip of the needle would then lie in proximity, and slightly anterior, to the foramen ovale (Fig. 1).

Should the needle touch or penetrate the mandibular nerve, the patient may suddenly complain of a sharp pain along the lower jaw and the needle should be retracted a few millimetres.

After the end of the record the needles are rapidly withdrawn but compression of the areas for about one minute is maintained.

\section{Method of Recording and Inducing Sleep}

All the records were taken with an 8-channel apparatus (Ediswan) with an amplification of $4 \mathrm{~mm}$. for 20 microvolts, time constant of 0.3 seconds, and high frequency cut of $15 \%$ at $75 \mathrm{c} . / \mathrm{s}$. Recording was always done in series-connected chains, the usual arrangements being those shown in the illustrations. Additional electrodes were placed when necessary over the fronto-temporal, the sylvian, and the zygomatic regions.
In all cases, even though fully studied with scalp electrodes on previous occasions, a routine scalp E.E.G. was taken before the insertion of the needles. This lasted 15 to 20 minutes but usually overbreathing was omitted both to avoid the risk of a seizure or the appearance of increased muscle activity should a mild tetany be induced.

From the work of Gibbs, Fuster, and Gibbs (1948), Fuster, Gibbs, and Gibbs (1948), and from personal experience, scanty E.E.G. abnormalities in the routine records may be more easily demonstrated during the effect of relatively short-acting barbiturates. Either oral quinalbarbitone ("seconal") (194 records) or intravenous thiopentone ("pentothal ") (28) was therefore usually administered.

Sleep was always obtained with thiopentone but only 80 times out of 194 when quinalbarbitone was used. Fifty-seven patients with quinalbarbitone became drowsy without falling asleep, 28 became restless, and the remaining 29 were apparently unaffected. One of the patients who became restless abreacted and the record had to be interrupted. Quinalbarbitone was given by mouth, the capsules being repeatedly perforated with a pin to facilitate absorption. An initial dose of 3 grains was followed after 25 minutes by additional $1 \frac{1}{2}$ grains either if no fast activity (18 to $28 \mathrm{c}$./s.) appeared in the traces or if the patient was not yet drowsy. The first dose was usually given just before the introduction of the sphenoidal needle electrodes, and recording in the appropriate arrangement began within five to eight minutes before any effect of the drug appeared either clinically or electrically so that the induced changes could be followed.

Usually a period of five minutes of ordinary recording with sphenoidal electrodes in place was allowed before beginning the injection of intravenous thiopentone solution. Thiopentone ("pentothal ") $5 \%$ solution was injected intravenously at the rate of $1 \mathrm{ml}$. a minute irrespective of body weight until the patient was deeply asleep (disappearance of corneal reflex). ${ }^{*}$ The injection was then interrupted but on occasions resumed at the same rate when the patient woke up. The total amount varied from 5 to $19 \mathrm{ml}$. $(0.25$ to $0.95 \mathrm{~g}$.) but the second dose was usually much smaller than the first. With thiopentone two patients abreacted violently and two others less dramatically. The abreaction, however, came after a period of sleep and the record was then interrupted. Two of the patients with thiopentone began to cough so much that the record had to be stopped. The first one convinced us of the possible risks (with little advantage) of using pharyngeal electrodes, particularly during intravenous injection of thiopentone.

In our first 200 records, single or bilateral pharyngeal electrodes were introduced as well as bilateral sphenoidal electrodes. Several patients complained that the pharyngeal were more uncomfortable than the sphenoidal electrodes. As no additional information appeared to be given by the pharyngeal electrodes, a single electrode either on the chin or on the tip of the nose was then used

* A trolley with the equipment necessary for resuscitation and artificial respiration was kept at hand though never used. 
instead as a less active electrode in a chain including the right and left sphenoidal electrodes.

The effect of auditory, occasionally tactile, or visual stimuli was assessed at various depths of sleep. The patient was eventually awakened and the record continued for a few more minutes. Recording stopped when sleep was not obtained within one and a half hours after administration of quinalbarbitone. Usually before the end of the test a short exploration of the activity of scalp electrodes in other regions than the temporal ones was performed, paying attention to the amplitude and distribution of the barbiturate-induced fast activity. In all the cases when thiopentone was administered and in those without drugs about half an hour of recording gave sufficient information.

\section{Results}

Artefacts.-Artefacts were met on occasions mainly in the form of muscle action potentials, and usually disappeared after a few minutes of recording. Artefacts were rarely so troublesome as to mask the underlying activity. In over half of the cases no muscle activity disturbed the traces. Movement artefact was considerable together with muscle activity when the patient swallowed, talked, yawned, smiled, or cried. Pulse artefact was rare and was quickly corrected by pushing the needle one or two millimetres deeper. A very peculiar slow-wave artefact was met in one patient when one of the needles was probably in a small vein and a few drops of blood came out of the hollow needle. Again this was corrected by gently pushing the needle.

Normal Activity.-The activity that we consider normal as recorded with our technique from the "sphenoidal" electrodes is a low amplitude (up to 20 to 30 microvolts) mixture of waves (6 to $15 \mathrm{c}$./s.), without definite features. Often the trace appears nearly flat. The alpha rhythm is poorly represented, even when prominent over the scalp. When recognizable, it never exceeded about 30 microvolts and disappeared on opening the eyes or following a noise. Mental calculations at times increased the amount of muscle activity. In young subjects a greater amount of 4 to $7 \mathrm{c}$./s. activity than in adults was recognizable similar to that seen in scalp records from the temporal regions.

Barbiturate-induced fast activity of low amplitude (10 to 30 microvolts) could be seen from the sphenoidal electrodes at the time it appeared from the frontal scalp electrodes (both for oral quinalbarbitone and for intravenous thiopentone). In at least one-third of the cases after quinalbarbitone it was not recognizable at either sphenoidal electrode, but in 48 of the cases no fast activity was seen even from the scalp electrodes. Sleep changes were similar to those recorded from the scalp but sleep spindles were usually less frequently seen. $\mathrm{K}$ complexes could be recognized, though of low amplitude, añ often showed a phase reversal at each sphenoi@al electrode.

Abnormal Activity.-The criteria of abnorma製y were similar to those generally accepted for scatp recording. A summary of the results obtained in $2 \$ 0$ "sphenoidal" records obtained from 166 patients is shown in Tables I to V. The grouping is based $3 \mathrm{n}$ the number of records rather than on the number. of patients, as 50 subjects had more than one recof $\overrightarrow{\text { d }} \mathrm{d}$ taken with this technique. In these cases variations in the amount, type, and lateralization of the E.E.fi. abnormalities were often noticed. Seven of o o patients had four and one had six records takn with this technique over a period of time rangifig from two months to two years.

TABLE I

NO. OF SPHENOIDAL RECORDS IN THE SERIES

\begin{tabular}{|c|c|c|c|c|c|c|}
\hline \multicolumn{5}{|c|}{$\begin{array}{l}\text { No. of Sphenoidal Records in } \\
\text { each Patient }\end{array}$} & \multirow{2}{*}{$\begin{array}{c}\begin{array}{c}\text { No. of } \\
\text { Patients }\end{array} \\
116 \\
26 \\
16 \\
7 \\
1\end{array}$} & $\begin{array}{l}\text { No. of } \\
\text { Records }\end{array}$ \\
\hline $\begin{array}{l}\text { Once } \\
\text { Twice } . . \\
\text { Three times } \\
\text { Four times } \\
\text { Six times }\end{array}$ & $\begin{array}{l}\ldots \\
\cdots \\
\cdots \\
\cdots\end{array}$ & $\begin{array}{l}\cdots \\
\cdots \\
\cdots \\
\cdots\end{array}$ & $\begin{array}{l}\cdots \\
\cdots \\
\cdots \\
\cdots\end{array}$ & $\begin{array}{l}\cdots \\
\cdots \\
\cdots \\
\cdots\end{array}$ & & $\begin{array}{r}116 \\
52 \\
480 \\
280 \\
6 \%\end{array}$ \\
\hline Total & $\ldots$ & $\ldots$ & $\ldots$ & $\cdots$ & 166 & $250 \frac{\Omega}{(1)}$ \\
\hline
\end{tabular}

TABLE II



VARIABILITY OF NORMAL AND ABNORMAL ACTIिI WYY AT SPHENOIDAL. LEVEL IN 50 PATIENTS WITH REPE PTED SPHENOIDAL RECORDS

\begin{tabular}{|c|c|c|c|c|c|c|}
\hline \multicolumn{4}{|c|}{$\begin{array}{c}\text { No. of Sphenoidal } \\
\text { Records in Each } \\
\text { Patient }\end{array}$} & \multirow{2}{*}{$\begin{array}{r}\text { Constant } \\
18 \\
6 \\
2 \\
0\end{array}$} & \multirow{2}{*}{$\begin{array}{c}\text { Variable } \\
8 \\
10 \\
5 \\
1\end{array}$} & \multirow{2}{*}{ 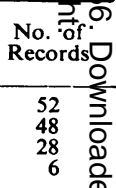 } \\
\hline $\begin{array}{l}\text { Two } \\
\text { Three } \\
\text { Four } \\
\text { Six }\end{array}$ & $\begin{array}{l}\cdots \\
\cdots \\
\cdots\end{array}$ & $\begin{array}{l}\cdots \\
\cdots \\
\cdots\end{array}$ & $\begin{array}{l}\cdots \\
\cdots \\
\cdots\end{array}$ & & & \\
\hline \multicolumn{3}{|c|}{ Total } & $\ldots$ & 26 & 24 & 134 \\
\hline
\end{tabular}

Quantitative differences of the abnormality have been disregarcod as only constancy or variability in laterality is considered (at the sphenoidal level).

TABLE III

SPHENOIDAL AND SCALP RECORDS COMPARED

\begin{tabular}{|c|c|c|c|c|}
\hline \multirow{2}{*}{$\begin{array}{l}\text { Sphenoidal } \\
\text { Records }\end{array}$} & \multicolumn{3}{|c|}{ Scalp Records } & \multirow{2}{*}{ Tota } \\
\hline & Normal & Doubtfully & Abnormal & \\
\hline $\begin{array}{lll}\text { Normal } & \ldots & \ldots \\
\text { Doubtfully } & \text { abnormal } \\
\text { Abnormal } & \ldots & \ldots \\
\end{array}$ & $\begin{array}{r}13 \\
0 \\
6\end{array}$ & $\begin{array}{r}27 \\
5 \\
21\end{array}$ & $\begin{array}{r}61 \\
7 \\
110\end{array}$ & $\begin{array}{r}101 \\
122 \\
1370\end{array}$ \\
\hline Total $\ldots$ & 19 & 53 & 178 & 250 \\
\hline
\end{tabular}

In the 69 records with bilateral abnormalities the sphenoidal electrodes one side was frequentPy more active than the other. The abnormalities weet mainly represented by sharp waves or spikes occasionally by slow waves. Local unilaterel 
TABLE IV

101 NORMAL SPHENOIDAL RECORDS

\begin{tabular}{|c|c|c|c|c|}
\hline Scalp E.E.G. & & $\begin{array}{l}\text { In-patients } \\
\text { with History } \\
\text { of Probable } \\
\text { Seizures }\end{array}$ & $\begin{array}{l}\text { In-patients } \\
\text { with no } \\
\text { Definite } \\
\text { History of } \\
\text { Seizures }\end{array}$ & Total \\
\hline $\begin{array}{l}\text { Normal . . } \\
\text { Doubtfully abnormal } \\
\text { Abnormal }\end{array}$ & $\begin{array}{l}\cdots \\
\cdots \\
\cdots\end{array}$ & $\begin{array}{r}3 \\
14 \\
50\end{array}$ & $\begin{array}{l}10 \\
13 \\
11\end{array}$ & $\begin{array}{l}13 \\
27 \\
61\end{array}$ \\
\hline Total & $\cdots$ & 67 & 34 & 101 \\
\hline
\end{tabular}

TABLE V

149 RECORDS WITH DOUBTFUL OR DEFINITE ABNORMALITIES AT SPHENOIDAL LEVEL

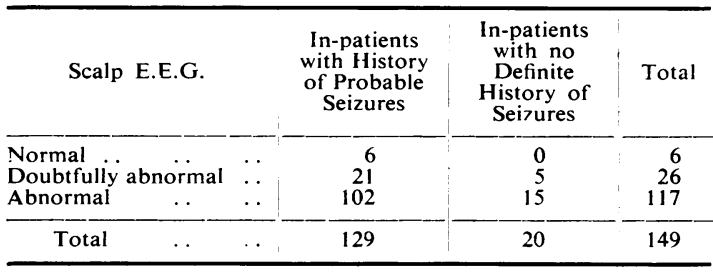

The site of the doubtful or definite abnormality was at the right sphenoidal electrode in 28 records, at the left one in 52 records, and at both in 69 records.

absence of barbiturate-induced fast activity in connexion with generalized discharges was considered an additional lateralizing sign of the abnormality (Pampiglione, 1952).

The E.E.G. abnormalities recorded from scalp electrodes and those from sphenoidal electrodes were rarely synchronous. Very often two or more focal discharges could be seen from the sphenoidal and temporal scalp electrodes, even though usually only one appeared to contain the elements of shortest duration. In four cases, synchronized discharges appeared which were fairly constantly focal at the same time both at the sphenoidal and homolateral mid-temporal electrodes.

Bilaterally synchronous discharges at both sphenoidal electrodes were very rare indeed and only in two of the 69 records with bilateral discharges at the sphenoidal level was there a predominant bilateral synchrony. In all the others the discharges usually appeared independently on either side. The location and lateralization of the most active focus appeared to change in some patients and not in others when the record was repeated at intervals from a few days to a few months (Table II). In many patients showing focal spike discharges from one temporal area no appreciable changes were recorded from the contralateral homologous region irrespective of the amplitude of the discharge. Very often large sharp waves or spikes recorded from sphenoidal electrodes were not represented by appreciable changes at the homolateral scalp electrodes (Fig. 3), and in six patients the scalp E.E.G. appeared normal throughout (Table III). The converse was often seen.

In two patients with a history of episodic behaviour disorders, and doubtful seizures, generalized bursts of 3 to $4 \mathrm{c}$./s. bilaterally synchronous spike-and-wave complexes were recorded from scalp electrodes. These complexes were rarely seen, and then only of low amplitude, from the sphenoidal electrodes, often slightly asymmetrical though bilaterally synchronous. Small amplitude sharp waves or small spikes were seen in addition to, and independently from, the spike-and-wave bursts. In both patients these small independent discharges were seen at the left sphenoidal electrode only.

In six cases of subsequently verified tumours involving the anterior half of the temporal lobe there was predominance of irregular slow waves

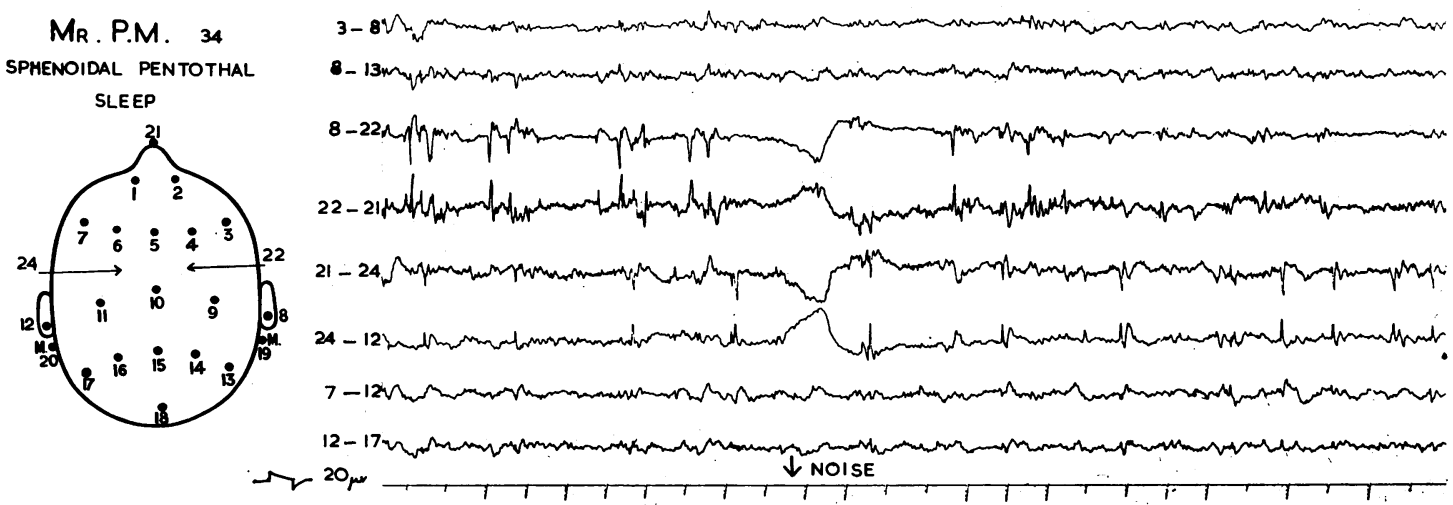

Fig. 3.-Frequent, apparently independent discharges are seen from either sphenoidal electrode while scanty abnormal activity is seen from scalp electrodes. A stimulus (noise) does not, in this case, much modify the abnormality. 
Miss P.A. 13 SPHENOIDAL RESTING

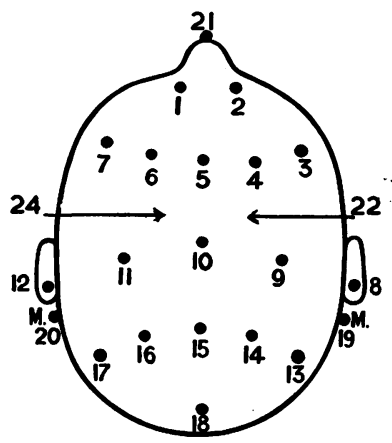

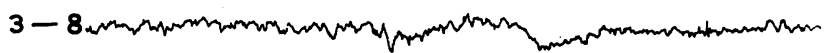

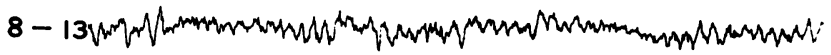
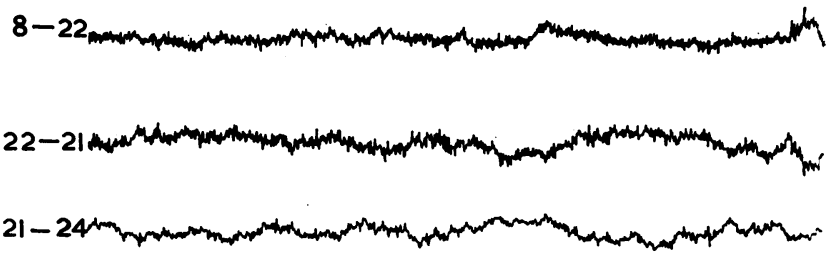

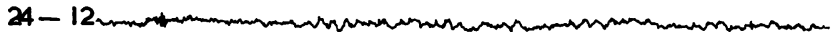

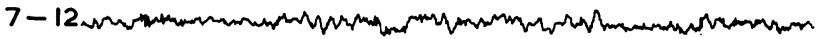

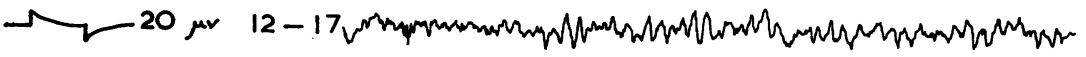

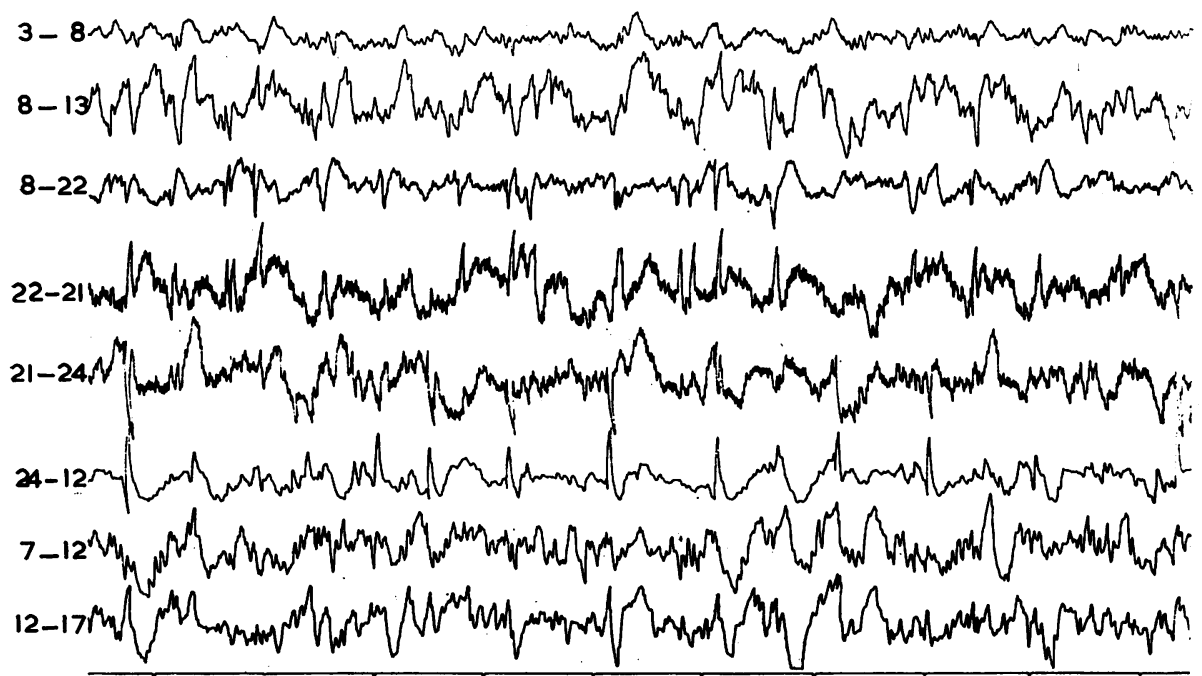

FIG. 4.-Above : the resting record with sphenoidal electrodes showed no gross abnormality. Below : the patient is asleep dufing intravenous thiopentone injection. A great deal of abnormality is seen from sphenoidal and scalp electrodes. Spikes and sharp waves appear independently over either hemisphere.

with rare spikes or sharp elements at the homolateral sphenoidal electrode, while the barbiturateinduced fast activity was markedly reduced locally.

In'five patients a record with sphenoidal electrodes was taken after a unilateral temporal lobectomy. (The operations had been carried out by Mr. M. A. Falconer and included excision of the uncus and anterior part of the hippocampal convolution.) Very little, if any, recognizable activity of cerebmal origin appeared to be picked up from the sphenoidgal electrode on that side in the first few weeks after the operation.

Barbiturates and Sleep.-The E.E.G. changes induced by barbiturates were also variable. Though 
Miss E.M. 20
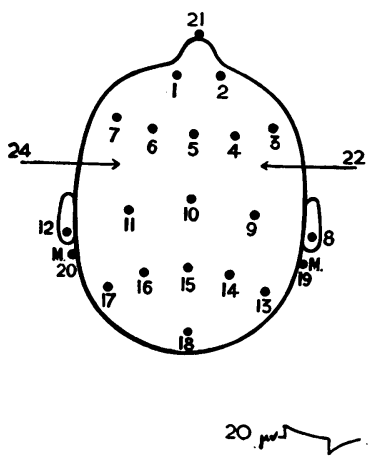
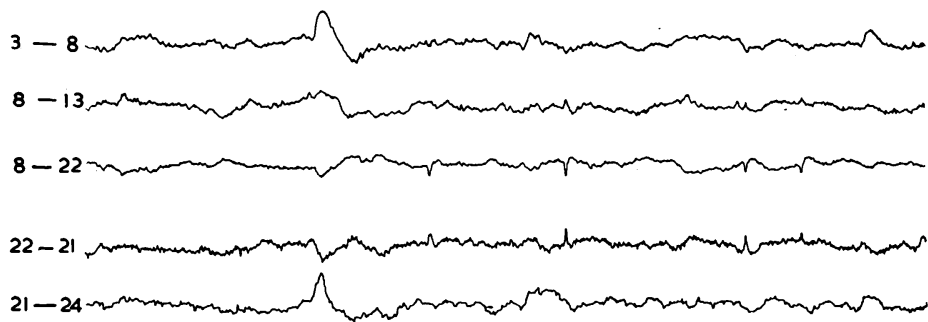

$24-12$

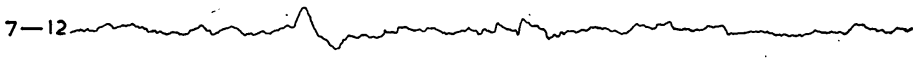

12-17

PENTO THAL SLEE $P$

- . . - -
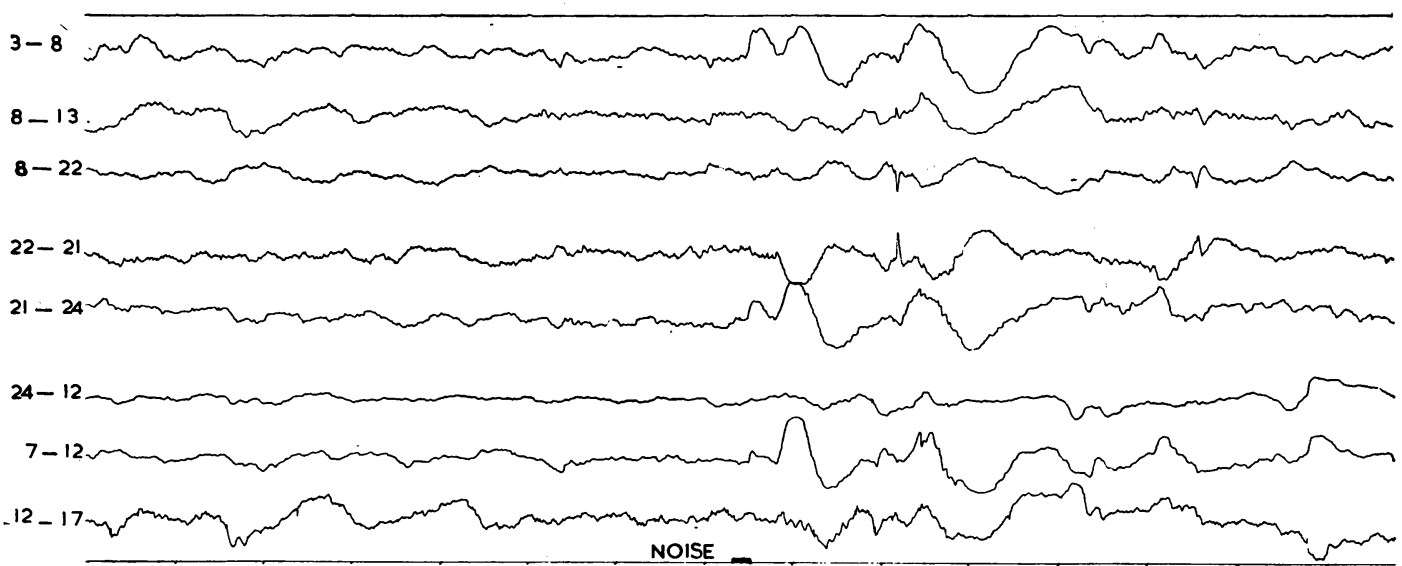

FIG. 5.-Patient asleep under thiopentone. Small unilateral discharges are seen with a fairly constant delay after apparently spontaneous (above) and evoked (below) $\mathrm{K}$ complexes.

the abnormalities (particularly spikes and sharp waves) were often increased (35) during the drowsy state or sleep (Fig. 4) sometimes there was no increase in the discharges and in three patients these disappeared during sleep.

In many cases the morphology and often the amplitude of the discharges changed during induced sleep even if the firing rate was not grossly changed. In four patients with unilateral discharges a contralateral independent discharge appeared during sleep (often even more actively firing than the original one) and disappeared again when the patient woke up. No bilateral synchrony was seen at any time in these cases.

During sleep and during the dozing state induced with either drug, sensory stimuli evoked various changes in the records. Apart from the appearance of normal changes ( $\mathrm{K}$ complexes), a short or prolonged focal discharge followed the stimulus in some cases. In three patients with intense firing, however, the discharges ceased following the stimulus. In two cases unilateral focal discharges appeared only following sensory stimulation during sleep (Fig. 5). Some patients showed E.E.G. abnormalities only at a certain level of sleep and not when too deeply or too lightly narcotized. But some patients showed abnormal discharges only when very deeply asleep, others only when just drowsy. These findings seem to parallel the interesting observations of Lairy-Bounes, Parma, and Zanchetti (1952) for strychnine spikes in rabbits. No adequate interpretation can be offered for these phenomena as yet.

Although intravenous thiopentone offers greater 
opportunity than oral quinalbarbitone for the study of various levels of sleep (and this can be done more than once in a few minutes) either drug has advantages and disadvantages (Aungle, Mitchell, and Pampiglione, 1954). Both have fairly similar effects on the E.E.G. No fits were induced by either drug in spite of the fact that occasional very intense firing was seen from one or more areas (Fig. 4). The advantages of using drugs which safely induce a state of changed functional activity of the brain are considerable, particularly in contrast with " metrazol".

\section{Discussion}

Technique.-The insertion of the needle electrodes is a surgical procedure, although a very minor one, and hence should be performed by a medically qualified person. As with all needle punctures, there would appear to be a minimal risk of sepsis but no infection has occurred in our series.

Slight pain accompanies the introduction of needle electrodes but is well tolerated by most patients. As mentioned above, local anaesthesia is hardly necessary, as the fine needle electrodes do not appear to cause more pain than the injection of the local anaesthetic. Some patients have complained of the local paraesthesiae that may follow the infiltration with local anaesthetic. A few patients complained of momentary severe pain along the jaw when the needle had almost reached its final position. We have presumed that this pain was due to the puncture of the mandibular nerve or its sheath as it ceased immediately the needle was withdrawn slightly. Deep infiltration with anaesthetic was avoided in contrast to the technique of Pertuiset and Capdevielle-Arfel (1951) and Jones (1951) as the preservation of pain sensation in the neighbourhood of the mandibular nerve may be a useful guide to the operator. In uncooperative patients we preferred to postpone the test rather than give a general anaesthetic.

We have been reluctant to apply this method in very restless and uncooperative patients and in young children. Similarly, we have also avoided investigating patients during a period in which they are having very frequent fits, as we were uncertain about the consequences of a fit with the needles in place. On two separate occasions one patient, a girl of 19, had a fit immediately after the insertion of one electrode and this was rapidly withdrawn by pulling the soldered lead. The insertion of the needle electrodes would seem to be dangerous only if one goes too far, when it would be theoretically possible to go behind and beyond the pterygoid laminae into the pharynx, or through the foramen ovale into the cavernous sinus and internal carotid artery. Though this would seem to require unusial enthusiasm, it must be remembered that should the foramen ovale be entered, its margin would then direct the needle. The length of our needle electrof is $5 \mathrm{~cm}$. and the above-mentioned points would ony seem to assume practical importance in an extremely

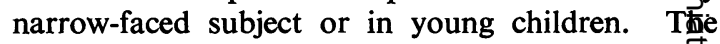
insertion is a simple procedure, well tolerated most patients, some of whom have had four or more investigations by this technique. Some hafe stated that they find it not so unpleasant as injection of "cardiazol" or photic stimulation, and some (admittedly few) have said that it $\frac{5}{7 s}$ preferable to the introduction of pharyngeal electrodes. There have been in our experience fo sequelae and the investigation has been often dome as an out-patient procedure and the patients allowed to go home by public transport, preferabsy accompanied by a relative, after a few hours' res?

In only one case the insertion of the need亞s appeared very difficult on either side. In this patient the radiograph showed an exceptiona $\bar{\phi}$ shallow mandibular notch; very little space ow therefore available for the horizontal introdug tien? of the needles under the zygomatic arch.

Reliability. $-X$-ray control pictures of the inserted electrodes were taken in 12 of our patients. The variability in the position of the tip of the needlewes within $1 \mathrm{c.cm}$. from the margin of the foramegn ovale in 11 people with average faces. IIt twelfth patient, with an exceptionally broad and fat face, the tips of the needles fully inserted were $1 \mathrm{in}$. lateral to the aimed point, though their direction was correct.

In order to check how much variability in pla ment of sphenoidal electrodes could be allowed for reliable recording, two patients were selected. $\overrightarrow{\mathrm{d} n}$ both a well localized spike focus at the anterior temporal region was firing frequently. The nee⿶ife electrode was withdrawn from the original placement in steps of $\frac{1}{2} \mathrm{~cm}$. while the record continued. appreciable change in the shape, duration, For amplitude of the focal spike was noticed up tơ withdrawal of about $1 \frac{1}{2} \mathrm{~cm}$. We consider, therefore, that a slightly imperfect insertion does not appoeciably alter the possibility of reliable recording, although a total error of more than $2 \mathrm{~cm}$. (laterafly to the foramen ovale) may alter the interpretation of the E.E.G. findings.

Electrodes on the scalp of the fronto-tempotal region or in the zygomatic region do not give reliaßle information on the activity of the inferior anterfor $r$ temporal region. Electrodes were placed around fronto-temporal and zygomatic region and their 

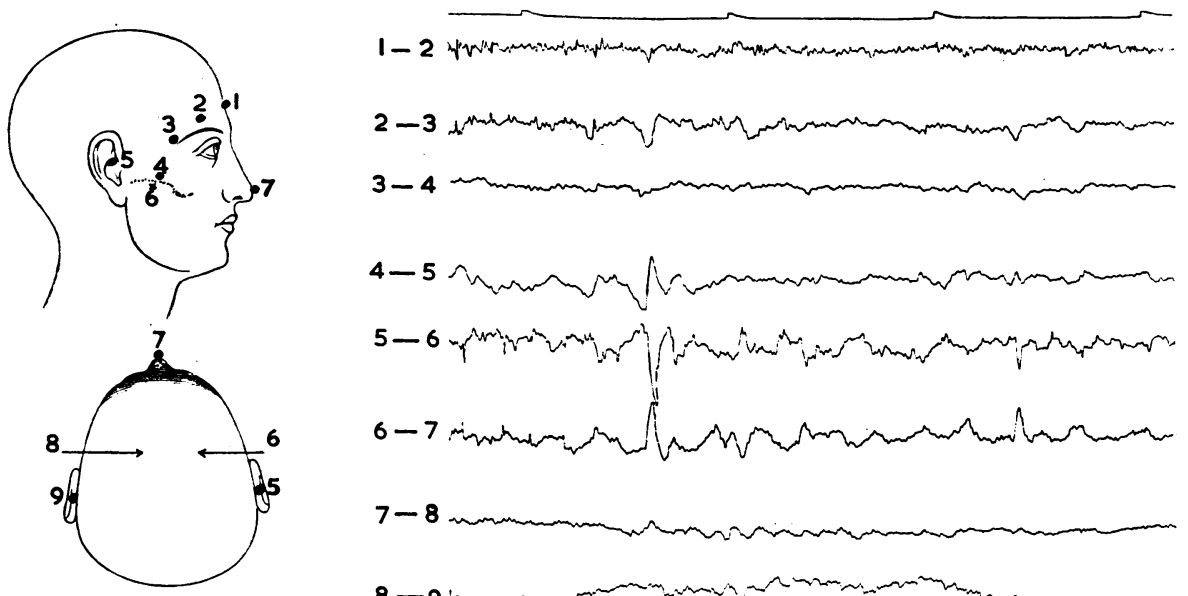

7-8

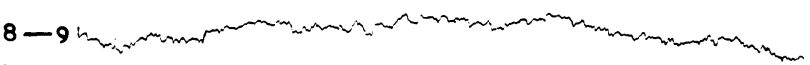

MR.R.F.H. 35 ح $20 \mu \nu$

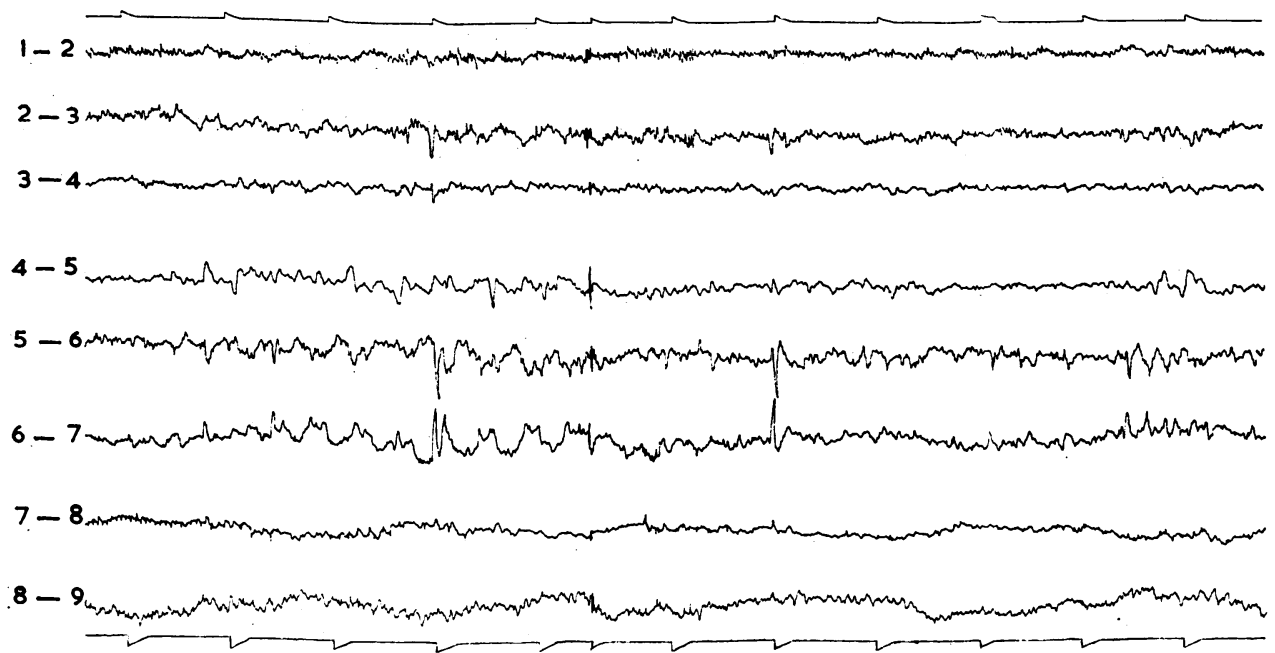

Fig. 6. - The discharges recorded from the right sphenoidal electrode are not always recorded from electrodes placed in the fronto-temporal and zygomatic region. There is no contralateral abnormality (patient awake).

activity was compared with that recorded at the same time from the homolateral sphenoidal electrode (Fig. 6). Though some of the discharges were similar, others were different, suggesting that the activity recorded from the scalp was probably not coming from the same source as that recorded from the sphenoidal electrode.

The reliability of recording with this technique has been checked with direct recording from the exposed brain at operation under local anaesthetic in 13 of our cases. The comparison of direct corticography and sphenoidal records suggests that though the latter method is rather crude in com- parison with the former, it gives fairly reliable information. It gives the possibility of differentiating cases in which the discharges are predominantly in the region of the uncus, the anterior part of the hippocampal and fusiform gyrus, or the temporal pole, from cases in which the discharges are predominantly on the lateral surface of the temporal lobe.

"Mirror Foci".- - In their recent book Penfield and Jasper (1954) define " mirror foci " as " transmitted disturbances from a cortical focus or area in one hemisphere to the homologous area of the opposite side. . . The primary spike may be shown 
to precede that from the mirror focus by 5 to 10 or even 15 milliseconds". They state also that the primary focal discharge is conducted over the principal commissural pathways directly to the opposite side (corpus callosum, anterior commissure, and commissure of the fornix).

In our series of cases the needle electrodes were always inserted on both sides and we could compare the activity of homologous areas in the anterior inferior aspect of the temporal lobe. In 69 cases the abnormalities recorded from the sphenoidal electrode were bilateral (Table V). A close scrutiny of the time-relationships of the discharges from each side showed that simple spikes or sharp waves were very rarely followed by contralateral disturbances within a few milliseconds.

In addition in 80 records most of the abnormalities were unilateral ( 52 on the left and 28 on the right) and in these cases very rarely could any appreciable disturbance be detected at the contralateral homologous sphenoidal electrode when a spike or a sharp wave appeared on one side. The so-called mirror foci in the abnormal activity of the temporal lobe were therefore in our material very uncommon, at least if we limit the term to Penfield and Jasper's definition. Penfield and Jasper also state that "in some cases the spike and sharp waves from the mirror focus appear just as rapid as those from the primary focus. . . . Even more disturbing is the fact that there may be occasional discharges from the mirror focus which are not immediately preceded by a spike from the primary focus". These conclusions raise the doubt as to whether and when it is justifiable to use the term mirror focus. In addition, if the definition of mirror foci proposed by Penfield and Jasper is used, such a phenomenon was very rare in our material, recording from both the lateral and the anterior inferior aspect of the temporal lobes.

Histological studies of the whole brain of epileptics who showed either unilateral or bilateral E.E.G. discharges in the inferior anterior temporal region might throw some light on this obscure problem. However, it may well be that the distribution of the electrical abnormalities has only an indirect and complex relationship with the distribution of the histologically demonstrable lesions. In the recent paper by Meyers (1954) there is an excellent discussion of the current premises underlying the approach to "the epileptogenic focus" and little at present can be added to it.

The variability in site and morphology of the E.E.G. abnormalities in many of our cases suggests that the demonstrable lesions may be only one of the factors related to the initiation and spread abnormal electrical discharges.

Underlying Lesions.-Unilateral temporal lobee tomy was performed by Mr. M. A. Falconer for the relief of epilepsy in 25 cases of our group and seriat histological studies of the tissue removed were performed by Professor A. Meyer (Falconer, 1953 Meyer, Falconer, and Beck, 1954). In the case where a clear local pathology was found (scars, malformations, or small tumours), this was ofte in the neighbourhood of the area of maximal electrical abnormality. In other cases the lesiors were not discrete.

The following case illustrates some of the proto lems met in this series of patients :-

J.P., a man, aged 23, was admitted under the care of Dr. Denis Hill. He was right-handed. His birth and infancy were normal. Generalized convulsions began at the age of 2 years and continued infrequently until the age of 12. Then the patient began to have a short-lived feeling of terror, with a peculiar epigastric sensation an the feeling of a threatening person behind him and to his left. This would occur several times a day (up to $\sqrt{6}$ times). On other occasions these feelings might be followed by loss of awareness, swallowing movements, 혀 far-away or frightened look, trembling of the haghds, dribbling saliva, sometimes followed by auton continuation of activities. On occasions he undressed himself. On other occasions he found himself in a he did not know. If he had one of these attacks in fgoit of somebody he would not dare to reappear in from of the same person. His attacks were not controlle宊 anticonvulsants, including a four months' tria $F$ \& "mysoline". He showed no abnormal neurological signs. A radiograph of the skull and an air encephale gram were within normal limits.

The first E.E.G. in May, 1950, showed focal sha waves in the right fronto-temporal region. In Septembe्कि, 1951 , some intermediate slow activity was seen over the right hemisphere without focal features. A sphenoide record at that time showed a clear spike focus at the right sphenoidal electrode (Fig. 7). This was more obvious when the patient was drowsy or asleep und

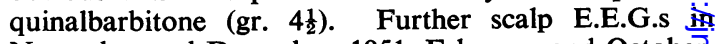
November and December, 1951, February and Octobe?, 1952 , and June, 1953, showed generalized abnormalitis without constant focal features though maximal in the right fronto-temporal region. Further sphenoidal studies revealed the constancy of the discharge of the shortest duration at the right sphenoidal electrode an no discharges from that of the left sphenoid. A right craniotomy was done by Mr. M. A. Falconer in June, 1953, and corticography revealed frequent abnorm discharges in the temporal lobe, the spikes of shortest duration being most frequently recorded from the anterior temporal region (particularly at the pole). Few abnormal discharges were independently seen in the middle and posterior temporal region and occasionally the inferior central region. The anterior half of the right 
MR. J.P. 21

21.9 .51

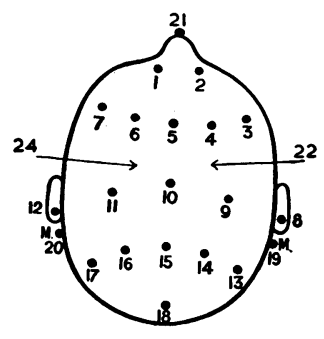

$-20 \mu v$

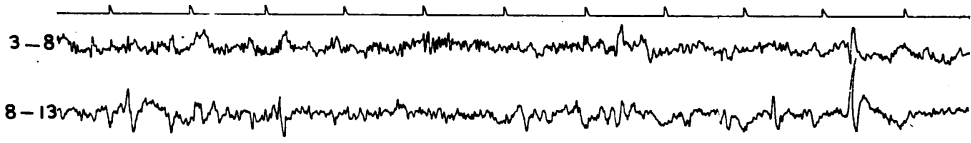

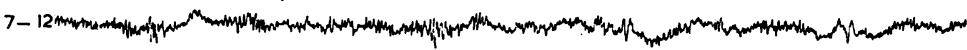

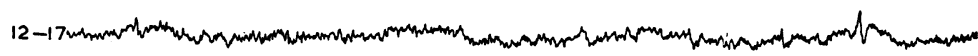

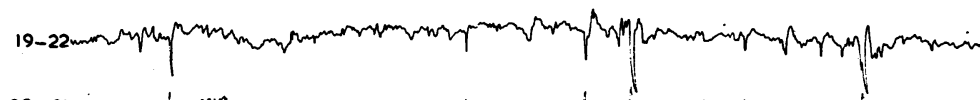
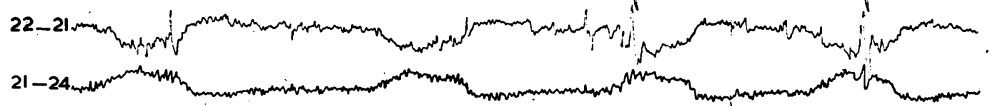

24-20 -

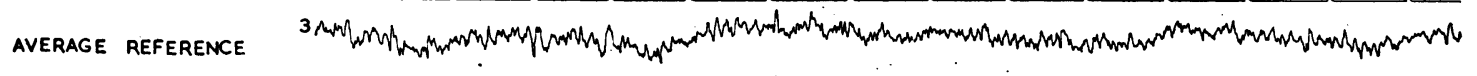

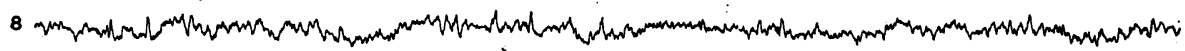

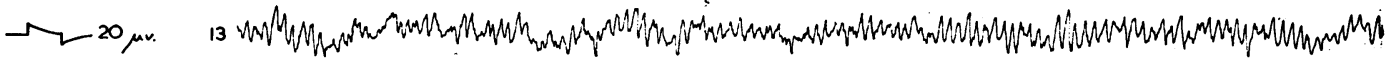

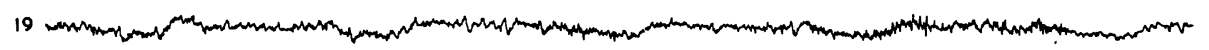

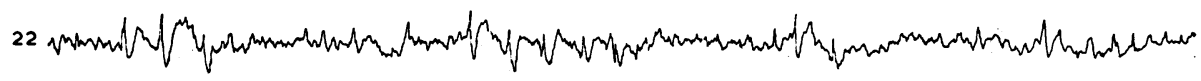

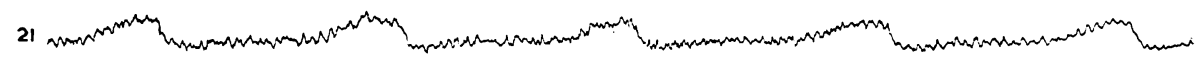

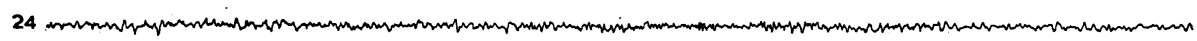

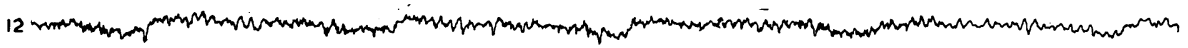

FIG. 7.-Above : standard bipolar chain recording (patient drowsy). Below : average reference recording (patient awake). Electrode 21 is a pharyngeal electrode, 19 and 20 are over each mastoid process, and electrodes 8 and 12 are in the concha of each ear as in most of our records.

temporal lobe, including the uncus and the anterior hippocampus, was removed. No macroscopic abnormalities were recognizable. Histological serial studies of the tissue removed were done by Professor A. Meyer and we are indebted to him for the following report :-

"There was almost total loss of neurons in the Sommer sector $\left(h_{1}\right)$ and the endfolium $\left(h_{3}-h_{5}\right)$ of the Ammon's horn which thus presented the typical picture of Ammon's horn sclerosis (Fig. 8). This lesion was definitely old and had led to shrinkage although glial fibre stains were not wholly successful. There was also fairly considerable marginal gliosis in all temporal convolutions available, occasionally severe, reaching into the upper layers. The cortex did not show obvious atrophy but showed status spongiosus throughout of a very recent origin, possibly due to oedema (prior to the operation). Status spongiosus was also occasionally encountered in the white matter which otherwise showed no pre-operative changes."

This patient, still on anticonvulsants, in the two years since his operation has had no more attacks of the previous kind, though on a few occasions he has had attacks with clonic movements of the face and jaw apparently in full consciousness.

The removed area, which showed abnormal electrical activity and included histological lesions, was probably involved in the development of some of this patient's seizures. He had never shown contralateral E.E.G. abnormalities, though followed up for a number of years, and had suffered from seizures since early childhood.

In other patients where repeated scalp and sphenoidal E.E.G.s showed multifocal abnormalities it was difficult to decide which area might be the most abnormal one.

The interpretation of E.E.G. findings in relation to the possible distribution of the underlying pathology cannot be discussed at this stage although material is being collected for such a study.

It might perhaps be possible in the future (after a 


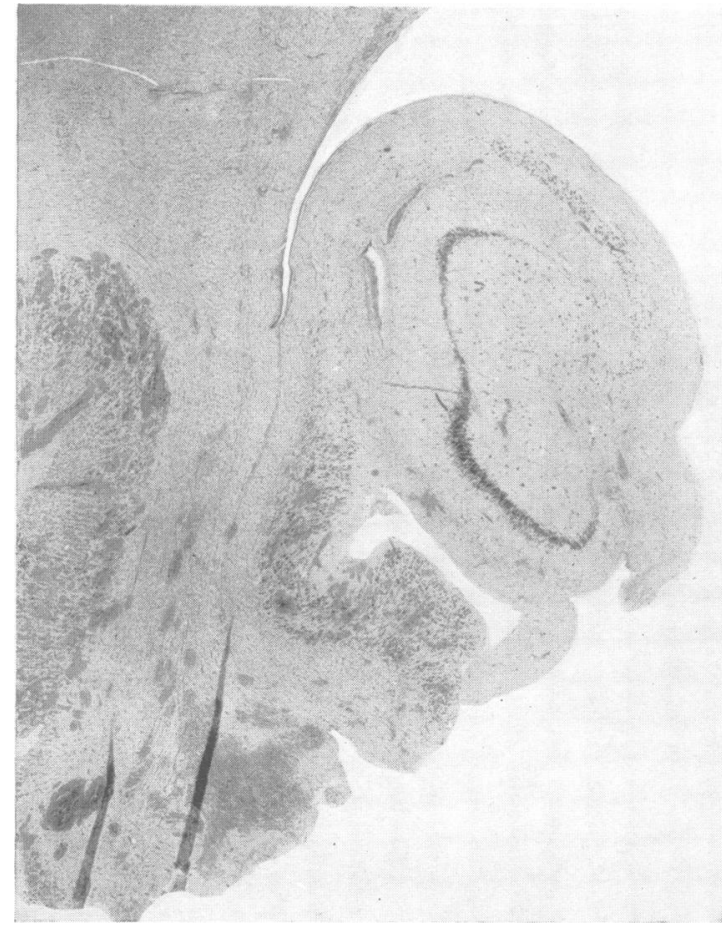

FIG. 8.-Section of Ammon's horn showing old sclerotic lesion with loss of cells in the Sommer sector and endfolium (patient J. P.). $\times 10$.

much larger series of cases with corticographic and histological studies) to assess whether electrically abnormal areas more active during the effect of barbiturates differ either in underlying pathology or site from areas showing diminished or unchanged activity in apparently similar conditions. Our impression is that the activation or inhibition of the discharges is more likely to be related to the functional state of structures concerned with the appearance or maintenance of sleep than due to a primary local pharmacological effect. The variation in the amount of discharges following sensory stimuli during barbiturate-induced sleep would perhaps be a point in favour of this view (Pampiglione, 1953).

\section{General Considerations}

Episodic Syndromes.-Forty-nine patients of our series had a history of attacks of doubtful nature, prolonged hallucinatory episodes, or periods of altered behaviour either with or without alleged amnesia. Clinically most of these patients might have been classified in the large, polymorphous group ranging from hysterical to schizophrenic syndromes. The interpretation of the clinical history sometimes changes in such patients according to the results of the various investigations. In nore of these patients, however, did the history include definite epileptic seizures. "Sphenoidal" recors were repeated in five of these 49 patients with a total of 54 records. In two repeats out of the five there was a difference between the first and second recor $\$$ the abnormality recorded at the sphenoidal levet being on both occasions unilateral at first and bilateral later.

Of these 49 patients nine (nine records) showed n⿳⺈⿴囗十一 E.E.G. abnormality either at scalp or sphenoid electrodes. Fourteen patients (15 records) showed doubtful abnormality from the scalp but none at the sphenoidal electrodes. In the remaining 26 patienes (30 records) the E.E.G. was abnormal at eithet scalp or sphenoidal level or both. Definite, of doubtful, abnormalities from either one or both sphenoidal electrodes were recorded from 16 patients (20 records).

The lack of any definite history of seizures these patients appears to introduce additional conplications in the clinical evaluation of the E. E. findings.

In all the other patients with a definite histor $\vec{P}$ seizures the E.E.G. abnormalities showed a good range of variability. A patient with seizures of the uncinate group may, or may not, show an E.E.G. abnormality only in the anterior inferior tempgrâ region. It is also impossible at present to guess whether in any given clinical case the susperted E.E.G. abnormality will be unilateral or bilateral. In addition, the morphology of the electric abnormalities recorded in the sphenoidal regions fails to show definite correlation with any particulär type of "temporal lobe" seizure, at least in owir present experience. In other words, there is n constant correlation between any particular type of clinical attack and the appearance of the E.E.G. abnormalities in the anterior inferior tempora regions. From repeated sphenoidal recordings of $\overline{\mathrm{g}}$ few patients the electrical abnormalities seemed to vary in location and morphology in some, while others very little change occurred over a period of many months.

We may conclude that this method of recording has given us valuable information about the activity of areas previously rarely explored. However, the gap between clinical and E.E.G. evidence and terminology is still very large.

\section{Summary}

A simple and safe method is described for the insertion of needle electrodes to the proximity $\&$ the foramen ovale (lateral approach) in order 
study the electrical activity of the anterior inferior regions of the temporal lobes.

The results of electroencephalographic investigations with bilateral "sphenoidal electrodes" are presented in a group of 166 patients largely selected on clinical grounds, an abnormality of function of the temporal lobes being suspected. All patients had previous routine scalp E.E.G.s with a total of 824 records. Two hundred and fifty additional E.E.G.s were taken with bilateral sphenoidal electrodes during the resting state and after the administration of drugs (mainly " seconal" and " pentothal ").

The criteria of normality and abnormality in the electrical activity of the anterior inferior part of the temporal lobes are discussed, including changes occurring during sleep and in response to sensory stimuli. Abnormalities in the E.E.G. taken with bilateral sphenoidal electrodes have been found in some patients in whom repeated routine scalp E.E.G.s were normal. Patients with a history of altered behaviour but without a definite history of seizures may show E.E.G. abnormalities maximal at either one or both sphenoidal electrodes.

The advantages and limitations of this method are discussed. Some observations upon the independence of abnormal activity between the temporal lobes in some epileptics are presented. The study of patients in whom an abnormality of function in the temporal lobe is suspected is considered in- complete without the additional technical procedure described.

Our thanks are due to Dr. Denis Hill, Dr. D. A. Pond, Dr. J. A. V. Bates, and Mr. M. A. Falconer for their advice and criticism, to the technical, recording, and secretarial staff of the Department of Clinical Neurophysiology for their continuous help, to Professor A. Meyer for his kind contribution and photomicrograph, to Dr. R. D. Hoare for his $x$-ray controls, and to Mr. P. V. Jacobs for the photographs.

\section{REFERENCES}

Aungle, P., Mitchell, W., and Pampiglione, G. (1954). Electroenceph. clin. Neurophysiol., 6, 344.

Falconer, M. A. (1953). Proc. roy. Soc. Med., 46, 971

Hill, D., Meyer, A., Mitchell, W., and Pond, D. A. (1955). Lancet, 1, 827.

Fuster, B., Gibbs, E. L., and Gibbs, F. A. (1948). Dis. nerv. System $9,199$.

Gastaut, H. et al. (1953). Epilepsia (Boston), 3 ser., 2, 59.

Gibbs, E. L., Fuster, B., and Gibbs, F. A. (1948). Arch. Neurol. Psychiat. (Chicago), 60, 95.

Hill, D. (1953). Proc. roy. Soc. Med., 46, 965.

Jasper, H. H. (1949). II International EEG Congress, Paris, 1949. Rapports Electroenceph. clin. Neurophysiol., Suppl. 2, 99.

Jones, D. P. (1951). Electroenceph. clin. Neurophysiol., 3, 100.

Kerridge, J. C. (1952). Ibid., 4, 254.

Kristensens and Reyes (1949). Quoted by Jasper, H. H., 1949

Lairy-Bounes, G. C., Parma, M., and Zanchetti, A. (1952). Electroenceph. clin. Neurophysiol., 4, 495.

Magnus, O. (1954). Folia psychiat. (Amst.), 57, 264.

Meyer, A., Falconer, M. A., and Beck, E. (1954). Journal of Neurology, Neurosurgery and Psychiatry, 17, 276.

Meyers, R. (1954). Epilepsia (Boston), 3 ser., 3, 9.

Pampiglione, G. (1952). Electroenceph. clin. Neurophysiol., 4, 79.

Pampigione, G. (1953). Epilepsia (Boston), 3 ser., 2, 91 .

Penfield, W., and Jasper, H. (1954). 2, Epilepsy and the Functional Anatomy of the Human Brain. Churchill, London.

Penman, J. (1953). Lancet, 1, 760.

Pertuiset, B., and Capdevielle-Arfel, G. (1951). Rev. neurol., Paris, $84,606$.

Taylor, J., ed. (1931). Selected writings of John Hughlings Jackson. Hodder and Stoughton, London. 